\title{
STUDI EXPERIMENTAL PEMANFAATAN SPEED BAMPER (POLISI TIDUR) MENJADI ENERGI LISTRIK MENGGUNAKAN PIEZOELEKTRIK
}

\author{
Abdurahim Sidiq, ${ }^{1, a}$, Gusti Rusydi Furqon Syahrillah, ${ }^{2, b}$, M. Isra" \\ Program Studi Teknik Mesin \\ Fakultas Teknik Universitas Islam Kalimantan (UNISKA) MAB \\ Jl. Adhiyaksa No. 2 Kayutangi Banjarmasin \\ Email: rahimsidias7a@gmail.com
}

\begin{abstract}
Abstrak
Inovasi dalam memenuhi kebutuhan energi listrik terus di lakukan oleh para ahli, baik dari terbarukan maupun energi alternative. Salah satu inovasi dalam kebutuhan energi listrik adalah dengan memanfaatkan Speed bump (Polisi tidur) menjadi energi listrik menggunakan piezoelektrik. Speed bamper (Polisi tidur) adalah gundukan yang dibuat melintasi di jalan untuk membatasi kecepatan laju kendaraan.

Speed bump (Polisi tidur) terdiri dari sistem mekanik gaya tekan dengan memanfaatkan 38 disk piezoelektrik yang susun secara seri sebagai sumber energi listrik dan 38 per pegas tekan od : $18 \mathrm{~mm}$, kawat 1,5 mm panjang 4,5 cm, Speed Bumper (polisi tidur) ini yaitu melewatkan sepeda motor dan berat penumpang sebagai media tekanan. Proses Pengujian alat Pembangkit Listrik Tenaga Piezoelektrik Dengan Menggunakan Media Speed Bumper ini yaitu melewatkan sepeda motor dan berat penumpang sebagai media tekanan sehingga untuk mengkonversi gaya tekan pada speed bumper (polisi tidur) piezoelektrik yang di kontak langsung ban kenderaan bermotor sehinga menjadi energi listrik. alat ini berhasil mengahasilkan pembangkit listrik dengan tegangan listrik terbaik pada saat penguijan yaitu 17,88 Volt dan arus listrik 0,39 Ampere sehingga mendapatkan daya listrik dengan hasil perhitungan yaitu 6,97 Watt dan rata - rata daya listrik yang dihasilkan yaitu 2,378 Watt.
\end{abstract}

Kata Kunci : Polisi Tidur, Piezoelektrik, Konversi

\section{Abstract}

Innovations in meeting the needs of electrical energy continue to be carried out by experts, both from renewable and alternative energy. One of the innovations in the need for electrical energy is by utilizing a speed bump into electrical energy using piezoelectricity. A speed bamper is a bump that is made across the road to limit the speed of the vehicle.

Speed bump consists of a compression force mechanical system utilizing 38 piezoelectric disks arranged in series as a source of electrical energy and 38 per compressive spring od: $18 \mathrm{~mm}$, wire $1.5 \mathrm{~mm}$ long $4.5 \mathrm{~cm}$, Speed Bumper This is to pass the motorbike and passenger weight as a pressure medium. The Testing Process of a Piezoelectric Power Plant Tool Using the Speed Bumper Media, which is to pass the motorbike and the passenger's weight as a pressure medium so as to convert the compressive force on the piezoelectric speed bumper which is in direct contact with the tires of motorized vehicles so that they become electrical energy. This tool succeeded in producing a power plant with the best electric voltage at the time of testing, namely 17.88 volts and an electric current of 0.39 Amperes so that it obtained electrical power with the calculation results of 6.97 watts and the average power generated was 2.378 watts.

Keywords: Speed bump, Piezoelectric, Conversion 


\section{PENDAHULUAN}

Hal ini karna inovasi dalam memenuhi kebutuhan energi listrik terus di lakukan oleh para ahli, baik dari terbarukan maupun energi alternative. Salah satu inovasi dalam kebutuhan energi listrik adalah dengan memanfaatkan Speed bump (Polisi tidur) menjadi energi listrik menggunakan piezoelektrik. Speed bamper (Polisi tidur) adalah gundukan yang dibuat melintasi di jalan untuk membatasi kecepatan laju kendaraan. Fungsi polisi tidur adalah untuk menjaga keteraturan berlalu lintas dan juga menjaga agar para pengendara kenderaan bermotor untuk memperlambat laju kenderaan. Dalam persoalan ini speed bumper (polisi tidur) dapat dimanfaatkan sebagai salah satu sumber energi yang terbarukan guna dalam menghasilkan energi listrik. Piezoelektrik adalah suatu kemampuan yang dimiliki sebagian Kristal yang dapat menghasilkan arus listrik jika mendapatkan perlakuan tekanan.Efek piezoelektrisitas dapat dimanfaatkan untuk mengubah energi mekanik menjadi energi listrik.

Proses perubahan energi ini membutuhkan bahan yang di sebut piezoelektrik. Bahan piezoelektrik merupakan sebuah bahan yang dapat mengeluarkan tegangan listrik jika bahan tersebut terkena sesuatau getaran dan tekanan Piezoelektrik sebuah bahan yang memiliki sifat yang unik. Penerapan getaran/tekanan pada keristal piezoelektrik terdiri dari beberapa domain interlocking yang memiliki muatan positif dan negative.

Berdasarkan latar belakang di atas, maka dapat di rumuskan masalahan yang akan di teliti dalam penelitian ini yaitu :

1. Bagaimana cara pembuatan alat Speed Bumper (polisi tidur) menggunakan media piezoelektrik?

2. Berapa besar daya listrik yang dihasilkan akibat pengaruh pembebanan tekanan yang bervariasi pada piezoelektrik?

Tujuan dari penelitian ini adalah :
1. Untuk mengetahui cara pembuatan alat Speed Bumper (polisi tidur) menggunakan media piezoelektrik.

2. Untuk mengetahui daya listrik yang dihasilkan akibat pengaruh pembebanan tekanan yang bervariasi pada piezoelektrik.

\section{METODE PENELITIAN}

Pelaksanaan penelitian dari bulan April 2020 Sampai dengan agustus 2020 pembuatan dan pengujian yang berlokasi di Jl. Cinta mulia RT 19, block A 1, Banjarmasin.

Alat

Alat yang akan digunakan dalam penelitian ini yaitu :

Tabel 3.1 Alat

\begin{tabular}{|c|l|c|}
\hline No & \multicolumn{1}{|c|}{ Nama Alat } & Jumlah \\
\hline 1 & Gergaji & 1 \\
\hline 2 & Palu & 1 \\
\hline 3 & Mesin Katam & 1 \\
\hline 4 & Meteran & 1 \\
\hline 5 & Solder & 1 \\
\hline 6 & Gerinda Tangan & 1 \\
\hline 7 & Gunting & 1 \\
\hline 8 & Bor Mesin & 1 \\
\hline 9 & Siku & 1 \\
\hline 10 & Multimeter Digital & 1 \\
\hline
\end{tabular}

\section{Bahan}

Berikut merupakan beberapa bahan yang digunakan untuk penelitian ini adalah :

Tabel 3.2 Bahan

\begin{tabular}{|c|l|c|}
\hline No & \multicolumn{1}{|c|}{ Nama Bahan } & Jumlah \\
\hline 1 & $\begin{array}{l}\text { Kayu Ulin bentuk balok } \\
\text { panjang 3 m dan lebar 10 } \\
\text { cm }\end{array}$ & 2 \\
\hline 2 & $\begin{array}{l}\text { Kayu Ulin bentuk papan } \\
\text { panjang 1,5 m dan lebar } \\
11,5 \text { cm }\end{array}$ & 8 \\
\hline 3 & $\begin{array}{l}\text { Kayu ulin bentuk kasau } \\
\text { panjang 3 m dan lebar 5 } \\
\text { cm }\end{array}$ & 2 \\
\hline 4 & Pegas Tekan (per tekan) & 40 \\
\hline 5 & Karet Selir Ban & 1 \\
\hline 6 & $\begin{array}{l}\text { Steropom / Gabus panjang } \\
1 \text { meter lebar 1 meter }\end{array}$ & 1 \\
\hline 7 & Kabel vero 1 meter & 1 \\
\hline 8 & Piezoelektrik disk 35 mm & 40 \\
\hline 9 & Baut 10 & 4 \\
\hline 10 & Baut 12 & 2 \\
\hline 11 & Paku Ulin, Paku Papan & 2 ons \\
\hline 12 & Lem Plastik & 1 \\
\hline
\end{tabular}




\begin{tabular}{|c|l|c|}
\hline 13 & Sekrup & 100 \\
\hline 14 & Double Tipe & 1 \\
\hline 15 & Dioda 2 Ampere & 4 \\
\hline \multicolumn{2}{|c|}{ Metode penelitian ini dilakukan }
\end{tabular}
menggunakan metode analisa yang dimana mengukur tegangan listrik rata-rata dan energi mekanik berupa memanfaatkan tekanan yang dihasilkan dari mobil dan motor.

\section{Langkah Penelitian}

Pengumpulan Data

Pada proses ini pengumpulan data di peroleh dari karya ilmiah yang pernah di tulis peneliti sebelumnya seperti jurnal, skripsi dan lain - lain sebagai referensi perancangan alat.

Perancangan Pembangkit Listrik Tenaga Piezoelektrik Dengan Menggunakan Media Speed Bumper

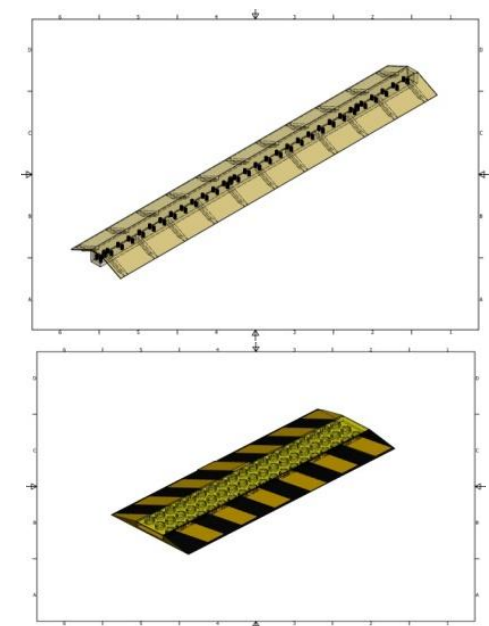

Gambar 3.1 Desain Rancangan

Sumber : Dokumen Pribadi

Dalam pembuatan Speed Bumper ini, tahap kerja utama yang dilakukan adalah membuat gambar desain Speed Bumper.Dimana desain rancangan bangun dibuat menggunakan software Inventor 2016. Tujuan pembuatan gambar ini untuk mempermudah pembuatan sesuai dengan keinginan dan langkah kerja.

Penyiapan Alat dan Bahan

Penyiapan alat dan bahan penelitian berdasarkan yang butuhkan sesuai penelitian ini yang berupa pembikinan alat Pembangkit Listrik
Tenaga Piezoelektrik Dengan

Menggunakan Media Speed Bumper.

Tahapan Pengerjaan Bahan

Setelah tahap membuat gambar selesai langkah selanjutnya adalah membuat persiapan bahan dengan kayu ulin dan kayu ulin kayu balok, karet selir ban, steropom, per tekan. Adapun tahapanya sebagai berikut :

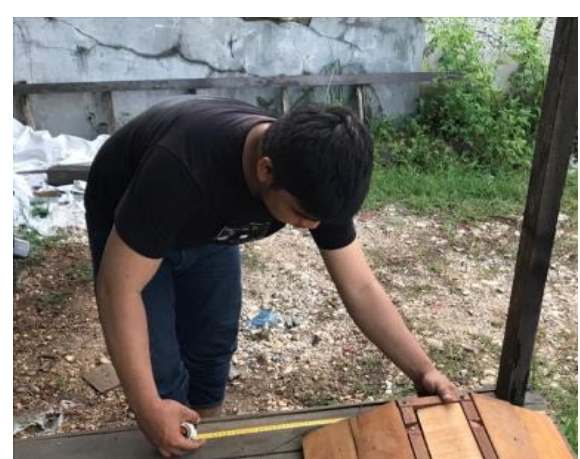

Gambar 3.2 Proses Pengerjaan Bahan

Sumber : Dokumen Pribadi

- Pengukuran, pemotongan dan pengataman pada kayu ulin balok setelah itu di pahat sesuai ukuran yang sudah ditentukan seperti desain perancangan.

- Pemotongan kayu kasau ulin untuk menjadikan landasan seperti ukuran yang sudah ditentukan.

- Pengukuran dan pemotongan kayu ulin papan sesuai ukuran yang ditentukan..

- Pengukuran kemiringan pada polisi tidur.

- Perakitan semua bahan kayu ulin sehingga menjadi sebuah rangka speed bumper.

- Peletakan steropom / Gabus sebagai alas buat piezoelektrik.

- Penyusunan per tekan di atas material piezoelektrik setelah itu di tutup dengan kayu papan sebagai media penekan ketika di lintasi.

Pengujian Alat

Pada pengujian ini di fokuskan pada alat Speed Bumper (polisi tidur) untuk berfungsi dengan baik untuk mengkonversikan dari Energi Mekanik menjadi Energi Listrik.

Hasil dan Analisa 
Hasil dan Analisa akan dilakukan yaitu mengenai pembuatan alat Speed Bumper (Polisi Tidur) dan fungsi kinerja alat Speed Bumper (Polisi Tidur).

\section{HASIL DAN PEMBAHASAN}

Aspek Teknis

Proses pembuatan speed bamper (polisi tidur) piezoelektrik ini terbuat dari kayu ulin yang di rakit sehingga menjadi speed bamper (polisi tidur), terdiri dari kayu2 ulin yang sudah di siapkan seperti kayu balok ulin 5.10 panjang 3 meter sebagai wadah untuk peletakan material piezoelektrik, kayu kasau ulin panjang 3 meter di potong sebagai rangka kaki landsan dengan kemiringan 23 derajat dan pemasangan kayu papan ulin. Perakitan piezoelektrik dengan menggunakan rangkaian seri sebanyak 38 disk piezoelektrik dan pemasangan per pegas tekan sebanyak 38 pcs dengan ukuran od: $18 \mathrm{~mm}$, kawat $1,5 \mathrm{~mm}$ panjang $4,5 \mathrm{~cm}$ untuk mengkonversi gaya tekan pada speed bamper (polisi tidur) piezoelektrik yang di kontak langsung ban kenderaan bermotor sehinga menjadi energi listrik.

Perancangan Alat Speed Bumper

Hasil dari proses perancangan desain alat Speed Bumper (polisi tidur) dan pengumpulan alat dan bahan yang sudah ditentukan sehingga dirakit menjadi alat Pembangkit Listrik Tenaga Piezoelektrik Dengan Menggunakan Media Speed Bumper. Langkah - langkah pembuatan dan perakitan alat Speed Bumper (polisi tidur) piezoelektrik ini terbuat dari kayu ulin yang di rakit sehingga menyerupai seperti polisi tidur, terdiri dari sistem mekanik gaya tekan dengan memanfaatkan 38 disk piezoelektrik yang susun secara seri sebagai sumber energi listrik dan 38 per pegas tekan od : $18 \mathrm{~mm}$, kawat $1,5 \mathrm{~mm}$ panjang $4,5 \mathrm{~cm}$, polisi tidur piezoelektrik yang di kenai kontak langsung ban kenderaan bermotor sehinga material piezoelektrik menyebabkan terjadinya perubahan energi mekanik menjadi energi listrik. Tahapan pembikinan sebagai berikut :

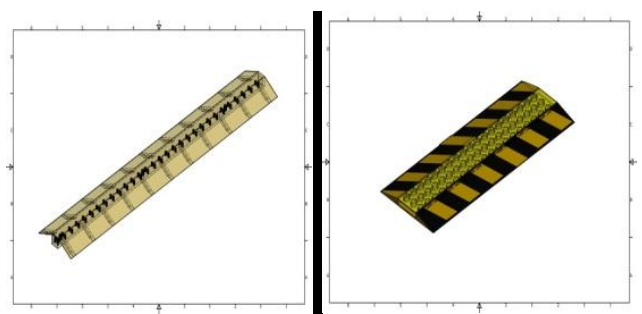

Gambar 4.1 Desain Rancangan

Sumber : Dokumen Pribadi

Tahapan Pembuatan Rangka Speed Bumper

Pada tahapan ini di lakukan pembikinan rangka speed bamper (polisi tidur), kayu ulin balok ukuran 3 meter di potong menjadi 2 meter $70 \mathrm{~cm}$, di katam dan pemahatan kayu balok sebagai penopang kaki kerangka yang sudah di ukur sesuai desain, setelah itu pemotongan kayu ulin kasau sebanyak 16 potongan dengan panjang $26 \mathrm{~cm}$ kemiringan 23 derajat sehingga membentuk seperti polisi tidur.

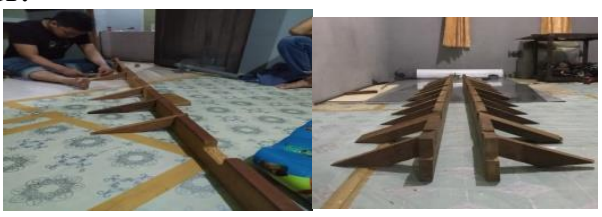

Pembuatan Rangka Speed Bumper

Sumber : (Dokumen Pribadi)

Tahapan Pemasangan Piezoelektrik

Pada tahapan ini kayu balok ulin sebgai wadah penempatan perangkaian piezoelektrik dan di tambahkan gabus sebagai alas yang berfungsi mengurangi kerusakan pada disk piezoelektrik.

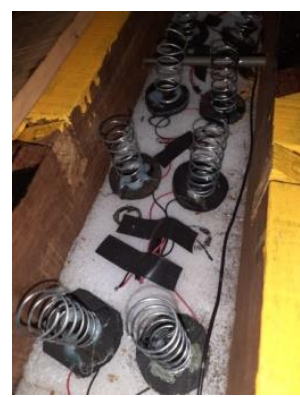

Gambar Perakitan Piezoelektrik

Sumber : Dokumen pribadi

Pemasangan beberapa material disk piezoelektrik yang satu dengan yang lain 
p-ISSN 2502-4922,e-ISSN 2615-0867

untuk membentuk suatu generator pembangkit yang menghasilkan tegangan dan arus yang di perlukan. Penyusunan piezoelektrik ini dengan rangkaian seri sebanyak 38 disk piezoelektrik dan di tambahkan karet yang di bentuk sama besarnya dengan piezoelektrik.

\section{Tahapan Pemasangan Karet Selir}

Pemasangan karet selir ban yang di pasang di atas kayu papan untuk menambah ketinggian landasan tengah speed bamper piezoelektrik

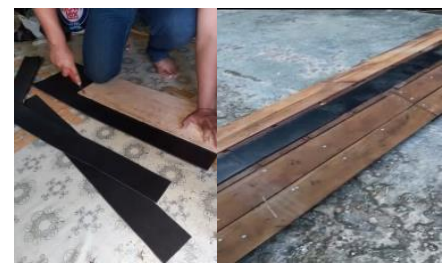

Gambar Proses Pemasangan Karet Selir Sumber : Dokumen Pribadi

Analisa Hasil Pengujian Alat

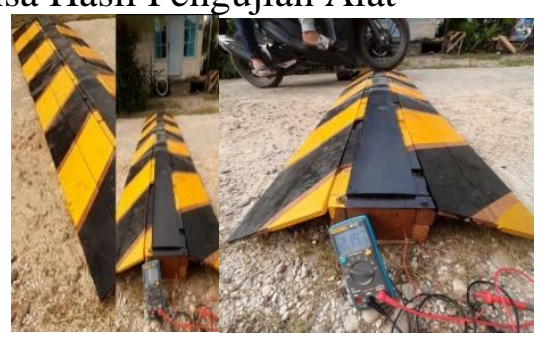

Gambar Proses Pengujian

Sumber : Dokumen Pribadi

Proses Pengujian alat Pembangkit Listrik Tenaga Piezoelektrik Dengan Menggunakan Media Speed Bumper ini yaitu melewatkan sepeda motor dan berat penumpang sebagai media tekanan sehingga Analisa hasil uji coba alat speed bumper dilakukan mengetahui tegangan listrik piezoelektrik dihasilkan saat proses pengujian sedangkan untuk mengukur arus listrik multimeter yang dipasang secara seri dan dihubungkan dengan accu 12 Volt 6 Ampere, Sedangkan daya listrik dihitung setelah mengetahui hasil arus dan tegangan listrik setelah proses pengujian. Berikut merupakan hasil analisa tahapan proses pengujian :
Tabel Hasil Arus Listrik dan Tegangan Listrik

\begin{tabular}{|c|c|c|c|}
\hline No & $\begin{array}{c}\text { Berat Spesifikasi } \\
\text { Kendaraan dan } \\
\text { Berat } \\
\text { Penumpang }\end{array}$ & $\begin{array}{l}\text { Arus } \\
\text { Listrik } \\
\text { (A) }\end{array}$ & $\begin{array}{c}\text { Tegangan } \\
\text { Listrik (V) }\end{array}$ \\
\hline 1 & $\begin{array}{l}\text { Yamaha Byson } \\
\text { dan Berat } \\
\text { Penumpang }\end{array}$ & 0,13 & 5,48 \\
\hline 2 & $\begin{array}{l}\text { Yamaha Mio } \\
\text { Sporty dan Berat } \\
\text { Penumpang }\end{array}$ & 0,24 & 9,87 \\
\hline 3 & $\begin{array}{l}\text { Yamaha Byson } \\
\text { dan Berat } \\
\text { Penumpang }\end{array}$ & 0,39 & 17,88 \\
\hline 4 & $\begin{array}{l}\text { Honda Vario } \\
125 \mathrm{cc} \text { dan } 2 \\
\text { Penumpang }\end{array}$ & 0,17 & 5,83 \\
\hline 5 & $\begin{array}{l}\text { Yamaha Byson } \\
\text { dan Berat } \\
\text { Penumpang }\end{array}$ & 0,15 & 6,07 \\
\hline 6 & Mobil RANGER & 0,34 & 15,75 \\
\hline
\end{tabular}

Grafik Hasil Arus Listrik (A)

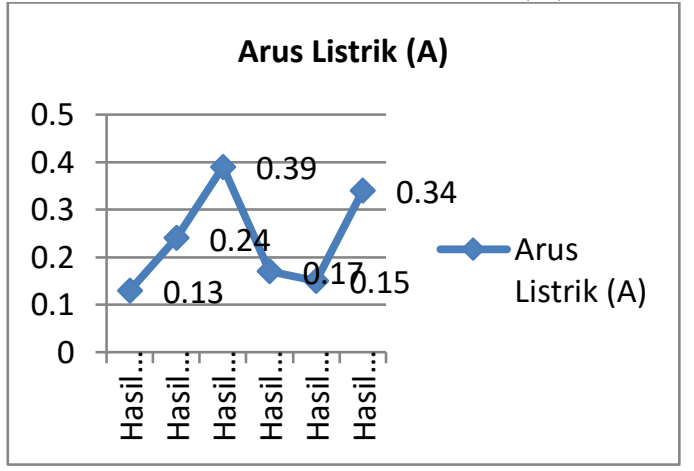

Grafik Hasil Tegangan Listrik (V)

\section{Tegangan Listrik (V)}

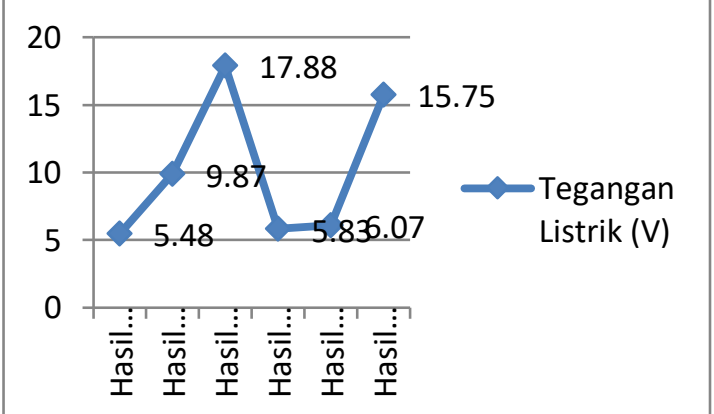

Dapat dilihat dari tabel hasil dan grafik pengujian diatas semakin besar berat kendaraan dan berat penumpang yang menekan pegas pada piezoelektrik maka semakin besar juga tegangan listrik 
yang dihasilkan, Pada saat pengujian arus dan tegangan listrik mengalami perbedaan sesuai dengan tekanan setiap melintasi Speed Bumper, hasil pengujian dengan hasil arus dan tegangan listrik terbaik yaitu 0,39A dan 17,88V. Untuk mengetahui hasil daya listrik maka dapat dihitung dengan penggunaan persamaan rumus Hukum Ohm karena arus dan tegangan listrik sudah diketahui dapat dilihat sebagai berikut :

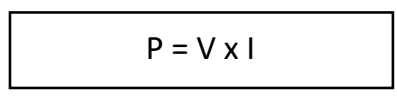

Keterangan :

$\mathrm{P}=$ Daya Listrik (Watt)

$\mathrm{V}=$ Tegangan Listrik (Volt)

$\mathrm{I}=$ Arus Listrik (Ampere)

Maka dapat dilihat hasil perhitungan daya listrik yang sudah diketahui arus listrik dan tegangan listrik dalam bentuk tabel sebagai berikut :

Tabel Hasil Perhitungan Daya Listrik

\begin{tabular}{|c|c|c|c|}
\hline NO & $\begin{array}{c}\text { Arus Litrik } \\
(\mathrm{A})\end{array}$ & $\begin{array}{c}\text { Tegangan } \\
\text { Listrik (V) }\end{array}$ & $\begin{array}{c}\text { Daya Listrik } \\
(\mathrm{W})\end{array}$ \\
\hline 1 & 0,13 & 5,48 & 0,75 \\
\hline 2 & 0,24 & 9,87 & 2,36 \\
\hline 3 & 0,39 & 17,88 & 6,97 \\
\hline 4 & 0,17 & 5,83 & 0,85 \\
\hline 5 & 0,15 & 6,07 & 0,96 \\
\hline 6 & 0,34 & 15,75 & 5,51 \\
\hline
\end{tabular}

Grafik Hasil Daya Listrik (W)

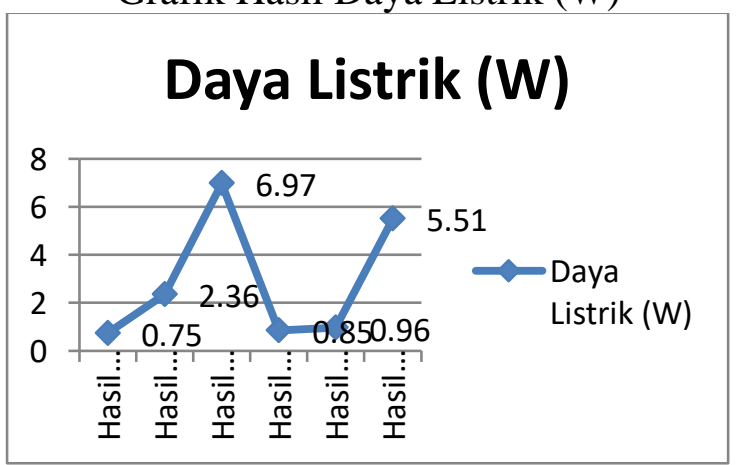

Dapat dilihat dari tabel dan grafik diatas merupakan hasil perhitungan daya litrik, alat Pembangkit Listrik Tenaga Piezoelektrik Dengan Menggunakan
Media Speed Bumper dapat menghasilkan daya listrik paling tinggi yaitu $6,97 \mathrm{~W}$, dapat dihitung nilai rata - rata daya listrik (W) yang dihasilkan dengan rumus sebagai berikut :

Hasil perhitungan rata - rata daya listrik (W) diatas yaitu 2,378 Watt maka dari setiap pengujian yang dilakukan bisa dikatakan alat ini berhasil mengahasilkan pembangkit listrik dengan tegangan listrik terbaik pada saat penguijan yaitu 17,88 Volt dan arus listrik 0,39 Ampere sehingga mendapatkan daya listrik dengan hasil perhitungan yaitu 6,97 Watt dan rata - rata daya listrik dari setiap pengujian yang dihasilkan yaitu 2,9 Watt.

$$
\begin{aligned}
& \text { Rata - rata Daya Listrik }(W) \\
& =\frac{\text { Jumlah Hasil Daya Listrik }(W)}{\text { Banyak Pengujian }}
\end{aligned}
$$

\section{KESIMPULAN}

Berdasarkan rumusan masalah dan tujuan penelitian, dapat di ambil kesimpulan sebagai berikut:

1. Alat ini di lakukan pembikinan rangka speed bamper (polisi tidur), yang terdiri dari kayu ulin balok ukuran 3 meter di potong menjadi 2 meter $70 \mathrm{~cm}$, di katam dan pemahatan kayu balok sebagai penopang kaki kerangka yang sudah di ukur sesuai desain, setelah itu pemotongan kayu ulin kasau sebanyak 16 potongan dengan panjang $26 \mathrm{~cm}$ kemiringan 23 derajat sehingga membentuk seperti speed bamper (polisi tidur), terdiri dari sistem mekanik gaya tekan dengan memanfaatkan 38 disk piezoelektrik yang susun secara seri sebagai sumber energi listrik dan 38 per pegas tekan od : $18 \mathrm{~mm}$, kawat $1,5 \mathrm{~mm}$ panjang 4,5 cm, Speed Bumper (polisi tidur) ini yaitu melewatkan sepeda motor dan berat penumpang sebagai media tekanan sehingga Analisa hasil uji coba alat speed bumper ( polisi tidur) dilakukan mengetahui tegangan listrik dari disk piezoelektrik. 
2 Hasil perhitungan rata - rata daya listrik (W) diatas yaitu 2,378Watt maka dari setiap pengujian yang dilakukan bisa dikatakan alat ini berhasil mengahasilkan pembangkit listrik dengan tegangan listrik terbaik pada saat penguijan yaitu 17,88 Volt dan arus listrik 0,39 Ampere sehingga mendapatkan daya listrik dengan hasil perhitungan yaitu 6,97 Watt dan rata - rata daya listrik yang dihasilkan yaitu 2,9 Watt.

\section{REFERENSI}

[1] Afif, m., \& rini, n. P. (2018).rancang bangun instalasi lampu pju termodifikasi ldr berbasis material piezoelektrik pada polisi tidur. Jurnal fisika flux: jurnal ilmiah fisika fmipa universitas lambung mangkurat, 14(2), 85-89.

[2] Almanda, d., dermawan, e., ramadhan, a. I., diniardi, e., \& fajar, a. N. (2015).analisis desain optimum model piezoelektrik pvdf untuk sumber pembangkit listrik air hujan berskala mini. Prosiding semnastek.

[3] Setianto, s., men, 1. K., \& abdurrochman, a. (2017).desain dan pemodelan sistem pembangkit listrik berbasis polisi tidur (studi pengaruh variasi kecepatan kendaraan terhadap respon speed bump model massapegas-peredam). Jiif (jurnal ilmu dan inovasi fisika), 1(1), 1-5.

[4] Yulia, e., putra, e. P., ekawati, e., \& nugraha, n. (2016).polisi tidur piezoelektrik sebagai pembangkit listrik dengan memanfaatkan energi mekanik kendaraan bermotor. Jurnal otomasi kontrol dan instrumentasi, 8(1), 105.

[5] Mowaviq, m. I., junaidi, a., \& purwanto, s. (2018). Lantai permanen energi listrik menggunakan piezoelektrik. Energi \& kelistrikan, 10(2), 112-118.

[6] Wijanto, e., harsono, b., renandy, r., septian, a., \& sutanto, k. (2018).pengujian sistem konversi energi suara menjadi energi listrik menggunakan piezoelektrik. Techné: jurnal ilmiah elektroteknika, 17(01), 59-67.

[7] Diniardi, e., syawaluddin, s., ramadhan, a. I., fithriyah, n. H., \& dermawan, e. (2018). Analisis daya piezoelektrik model hybrid solar cellpiezoelectric skala rendah. Jurnal teknologi, 10(2), 139-146 